LAWRENCE LIVERMORE NATIONAL LABORATORY

\title{
Measurement of Cu-Doped Be Gradient Steps in Sputtered Be Capsules
}

Robert C. Cook

$03 / 26 / 2004$

Work performed under the auspices of the U.S. DOE by UC, LLNL contract No. W-7405-Eng-48. 
This document was prepared as an account of work sponsored by an agency of the United States Government. Neither the United States Government nor the University of California nor any of their employees, makes any warranty, express or implied, or assumes any legal liability or responsibility for the accuracy, completeness, or usefulness of any information, apparatus, product, or process disclosed, or represents that its use would not infringe privately owned rights. Reference herein to any specific commercial product, process, or service by trade name, trademark, manufacturer, or otherwise, does not necessarily constitute or imply its endorsement, recommendation, or favoring by the United States Government or the University of California. The views and opinions of authors expressed herein do not necessarily state or reflect those of the United States Government or the University of California, and shall not be used for advertising or product endorsement purposes. 
Mail Station L-481

Ext: $2-3117$

March 26, 2004

To: $\quad$ Distribution

From: $\quad$ Bob Cook

Subject: Measurement of Cu-doped Be gradient steps in Sputtered Be capsules

\section{Introduction.}

The purpose of this memo is to lay the groundwork for non-destructively determining the position and ultimately the concentration of $\mathrm{Cu}$ gradient steps in sputtered Be capsules (or Ge steps in CH capsules) by "simple" radiography. A second personal objective was for me to learn something about radiography, and for that reason this memo may be more detailed than necessary.

Steve Haan has suggested a design for Be capsules that makes use of a gradient of $\mathrm{Cu}$-doping in a sputtered Be shell. ${ }^{1}$ The capsule for a $300 \mathrm{eV}$ design is shown in Figure 1. ${ }^{2}$

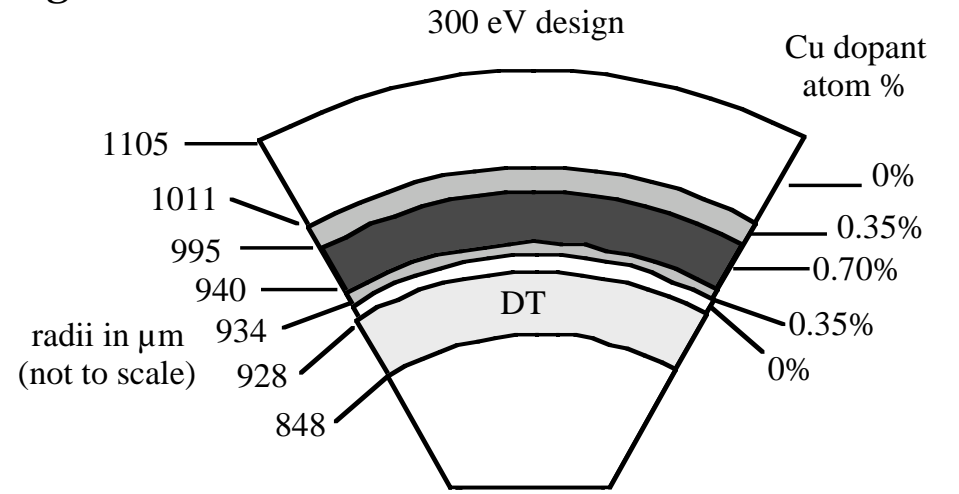

Ablator roughness specs on four designs

\begin{tabular}{cccc}
$\mathrm{T}_{\mathrm{R}}(\mathrm{eV})$ & $\mathrm{E}_{\mathrm{abs}}(\mathrm{kJ})$ & $\max \mathrm{Cu} \%$ & ablator $\mathrm{rms}$ \\
\hline 250 & 115 & $0.35 \%$ & $7 \mathrm{~nm}$ \\
250 & 300 & $0.35 \%$ & $100 \mathrm{~nm}$ \\
250 & 700 & $0.35 \%$ & $280 \mathrm{~nm}$ \\
300 & 200 & $0.70 \%$ & $220 \mathrm{~nm}$ \\
\hline
\end{tabular}

Figure 1. Be capsule with graded $\mathrm{Cu}$ dopant. The Be next to the DT fuel is undoped; the dopant rises to a maximum in two steps and then back down again. The $300 \mathrm{eV}$ design is shown. The $250 \mathrm{eV}$ designs are scales of the design by Dittrich. ${ }^{3}$ The table shows the allowed ablator rms roughness (1/3 of the ablator perturbation that causes $50 \%$ yield degradation, in modes 12 and above)

The question that this memo wants to address is whether the copper concentration boundaries (and ultimately the concentration itself) can be seen and measured with our radiography system. I will focus only on the relative opacities, and not get into the practicalities of film reading, lateral resolution and the like. I will assume a monochromatic $8 \mathrm{keV}$ source; clearly there are other sources and filters that

\footnotetext{
${ }^{1}$ Steve Haan, et al., Fusion Sci. and Technol, (2004), to be published. A copy of the paper can be obtained from Bob Cook.

${ }^{2}$ Figure and caption taken directly from the paper in reference 1.

${ }^{3}$ T. R. Dittrich, S. W. Haan, M. M. Marinak, S. M. Pollaine, and R. McEachern, "Reduced Scale National Ignition Facility Capsule Design," Phys. Plasmas 5, 3708 (1998)
} 
can be used, as well as the fact that the source is not monochromatic. So given all these approximations lets proceed.

\section{Background, material properties, and model.}

The transmittance of light through a material is governed by Beer's Law, which for x-rays is usually written as

$$
\frac{I(z)}{I_{0}}=e^{-\mu \rho z}
$$

where $I(z) / I_{0}$ is the fractional intensity transmitted through a distance $z$ filled with an element at density $\rho$ that has a mass attenuation coefficient of $\mu$. Since x-rays interact primarily with inner shell electrons one in general doesn't worry about the chemical nature of the atom, but rather simply with the density with which it fills space. The mass attenuation coefficients, which are the $x$-ray version of extinction coefficients, are generally given in units of $\mathrm{cm}^{2} / \mathrm{g}$, thus the densities must be given in $\mathrm{g} / \mathrm{cm}^{3}$ and the distance in $\mathrm{cm}$. For a transmission through a mixed media, such as $\mathrm{Cu}$-doped $\mathrm{Be}$, the attenuation of the elements is additive, thus

$$
\mu \rho z=\sum_{j}\left(\sum_{i} \mu_{i} \rho_{i}\right)_{j} z_{j}
$$

where the sum over $j$ is over the regions (lengths) where the composition is constant and the sum over $i$ is over the atomic constituents in that region.

The model shell we will look at is that pictured in Figure 1, except that instead of a DT ice layer there will be a $14 \mu \mathrm{m}$ thick $\mathrm{CH}_{1.3}$ plasma polymer shell on the inside of the Be ablator. Ultimately this will be thermally removed, but it is likely that our first looks at the shell will be with the mandrel still in place. The $\mu$ values at $8 \mathrm{keV}$ for the relevant elements that were used are given in Table $1{ }^{4}$ It is worth noting that for $\mathrm{Cu}$ the value is in this work an approximation, since the source is $\mathrm{Cu} 8 \mathrm{keV}$ falls very close to the absorption edge, the value of 50 is on the low side..$^{5}$

$\begin{array}{cc}\text { Table } 1 . \mu \text { values }\left(\mathrm{cm}^{2} / \mathrm{g}\right) \\ \text { element } & \mu \\ \mathrm{C} & 6.0 \\ \mathrm{H} & 0.4 \\ \mathrm{Be} & 0.8 \\ \mathrm{Cu} & 50.0\end{array}$

\footnotetext{
${ }^{4}$ These values were taken from The Handbook of Spectroscopy, J. W. Robinson, ed., CRC Press (1974).

${ }^{5}$ The value will depend upon the actual spectrum of the source. 50 is about right for monochromatic 8 $\mathrm{keV}$ photons. Thank you Bob Turner for help in understanding this.
} 
The densities of the various elements in their layers were calculated as follows. For the plasma polymer shell the density of $\mathrm{CH}_{1.3}$ is $1.05 \mathrm{~g} / \mathrm{cm}^{3}$, thus the densities of $\mathrm{C}$ and $\mathrm{H}$ are $12.0 / 13.3$ and 1.30/13.3 times this value or 0.947 and $0.103 \mathrm{~g} / \mathrm{cm}^{3}$ respectively. The density of pure Be was taken as $1.85 \mathrm{~g} / \mathrm{cm}^{3}$. For the $\mathrm{Cu}$-doped Be I simply assumed that atoms of $\mathrm{Cu}$ replaced atoms of Be without any volume change, thus the density of the Be in the doped sections is

$$
\rho(\text { Be in } \mathrm{Cu}-\text { doped layers })=1.85 \times \frac{(100-\text { atom \% Cu })}{100}
$$

The mass density of the $\mathrm{Cu}$ is given by

$$
\rho(\mathrm{Cu} \text { in } \mathrm{Cu}-\text { doped layers })=1.85 \times \frac{63.546}{9.012} \times \frac{\text { atom } \% \mathrm{Cu}}{100}
$$

where the first fraction on the right side is the ratio of atomic weights of $\mathrm{Cu}$ to Be. For the $\mathrm{CH}_{1.3}$ mandrel, pure $\mathrm{Be}, 0.35 \%$ and $0.70 \% \mathrm{Cu}$-doped Be the net values of $\mu \rho$ are given in Table 2.

\begin{tabular}{|c|c|}
\hline layer & $\mu \rho\left(\mathrm{cm}^{-1}\right)$ \\
\hline $\mathrm{CH}_{1.3}$ & 5.72 \\
\hline pure Be & 1.48 \\
\hline $.35 \%$ Cu-doped Be & 3.76 \\
\hline
\end{tabular}

Table 2. Values of $\mu \rho$ for various layers.

We now need distance information for the thickness of each layer as seen be $\mathrm{x}$ rays traveling through the capsule. We will model the capsule as a series of concentric spheres with origins at $(0,0)$ whose surfaces define the interfaces between layers, in general

$$
x^{2}+y^{2}+z^{2}=r_{j}^{2}
$$

where each $r_{j}$ represents a radial change in composition. For the capsule shown in Figure 1 there are 7 relevant $r_{j}$ 's listed in Table 3.

Table 3. Values of $r_{j}$ in $\mu \mathrm{m}$ taken from Figure 1.

\begin{tabular}{rr} 
interface & $\underline{r}_{j}(\mu \mathrm{m})$ \\
\hline inside of $\mathrm{CH}_{1.3}$ mandrel & 914 \\
mandrel/pure Be & 928 \\
pure Be/0.35\% Cu-doped Be & 934 \\
$0.35 \% / 0.70 \% \mathrm{Cu}$-doped Be & 940 \\
$0.70 \% / 0.35 \% \mathrm{Cu}$-doped Be & 995 \\
$0.35 \% \mathrm{Cu}$-doped Be/pure Be & 1011 \\
pure Be/outside of shell & 1105
\end{tabular}


If we take the x-rays as traveling in the $z$ direction, the chord length of a sphere of radius $r$ that is intercepted for an $\mathrm{x}$-ray at $(x, y)$ is

$$
\begin{aligned}
z & =2 \sqrt{r^{2}-x^{2}-y^{2}} \text { if } r^{2}>x^{2}+y^{2} \\
& =0 \text { otherwise }
\end{aligned}
$$

Thus for a specific layer (other than the outer layer) we have

$$
z_{j \text { th layer }}=2\left(\sqrt{r_{j}^{2}-x^{2}-y^{2}}-\sqrt{r_{j-1}^{2}-x^{2}-y^{2}}\right) \text { for } r_{j-1}^{2}>x^{2}+y^{2} .
$$

If the outer layer $\left(r_{j-1}=1011 \mu \mathrm{m}<\sqrt{x^{2}+y^{2}}<1105 \mu \mathrm{m}=r_{j}\right)$ then the second term of eq 7 is zero.

\section{Results.}

The problem is easily programmed. What will be shown are effectively "lineouts" through the center of the 2D projection of the shell on the $x y$ plane. Lets start with a uniform Cu-doped Be shell over a plastic mandrel, the results for $0.0 \%, 0.35 \%$ and $0.7 \% \mathrm{Cu}$ doping throughout the Be are shown in Figure 2. There are several things to note. First, what we will see is exposed film, thus the transmission curves are the ones to focus on. Second, both at the inside surface of the plastic and at the plastic/Be interface the curves are continuous but there is a discontinuous change in slope. This change can, however, be very small if the values of $\mu \rho$ for the materials on either side of the interface are similar. Such is the case for the plastic and $0.70 \% \mathrm{Cu}$-doped Be.

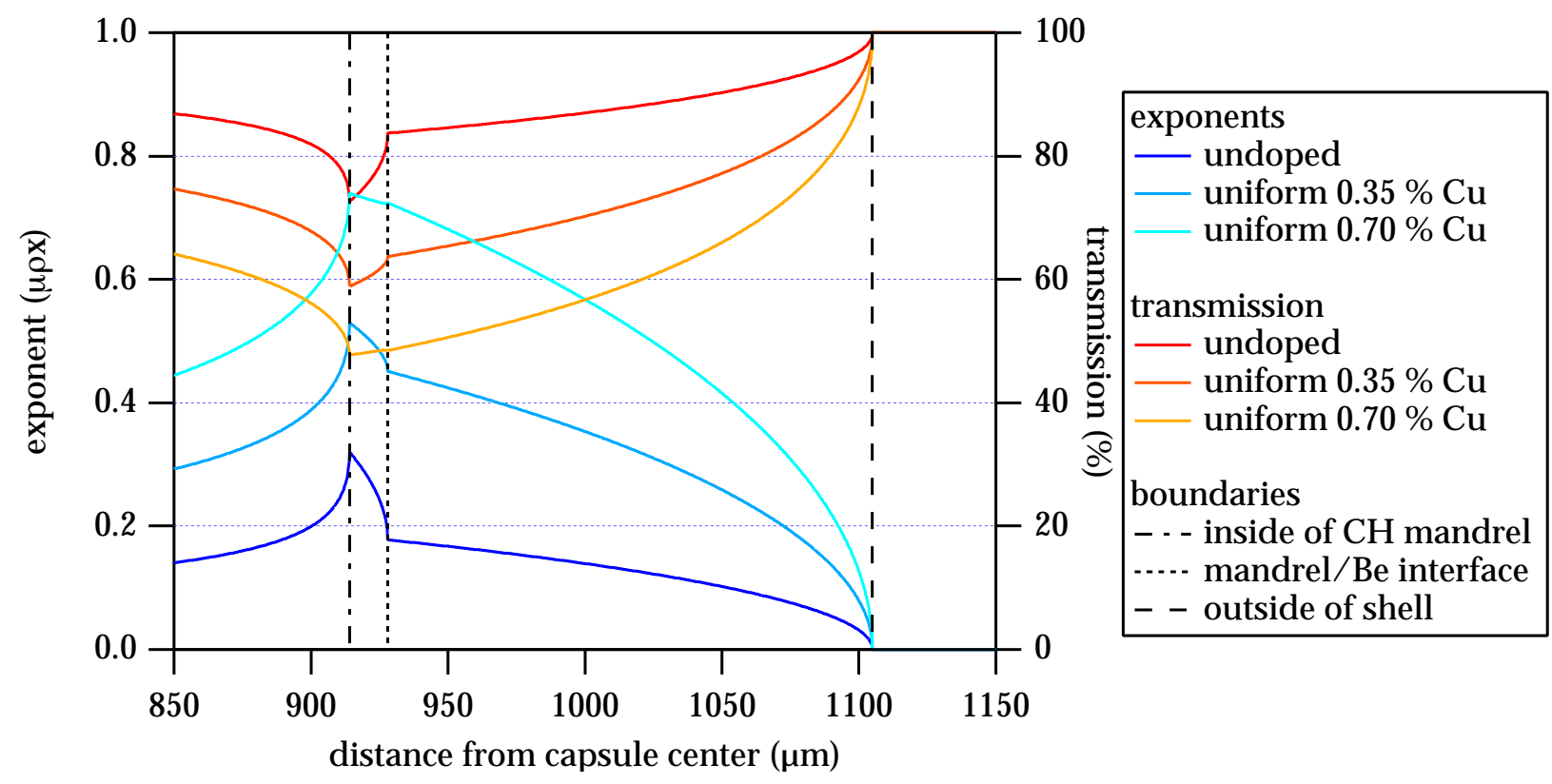

Figure 2. The left axis and blue curves show the exponent (eq 1) and the right axis and $\mathrm{red} / \mathrm{yellow}$ curve show the \% transmission of $8 \mathrm{keV}$ x-rays through a $2 \mathrm{~mm}$ Be shell with uniform $\mathrm{Cu}$-doping. The vertical black dashed lines show the position of the inside, outside and $\mathrm{CH} / \mathrm{Be}$ interface. 
Fortunately that situation doesn't come up in the gradient doped capsule where the plastic is in contact with undoped Be. In Figure 3 is a plot of what we would expect for the capsule described in Figure 1. What we see is distinct changes in slope at each interface. In Figure 4 I plot the derivative of the transmission with respect to radius (somewhat arbitrary units of $\Delta \% T / \mu m$ ), which accentuates the changes in slope at the interfaces.

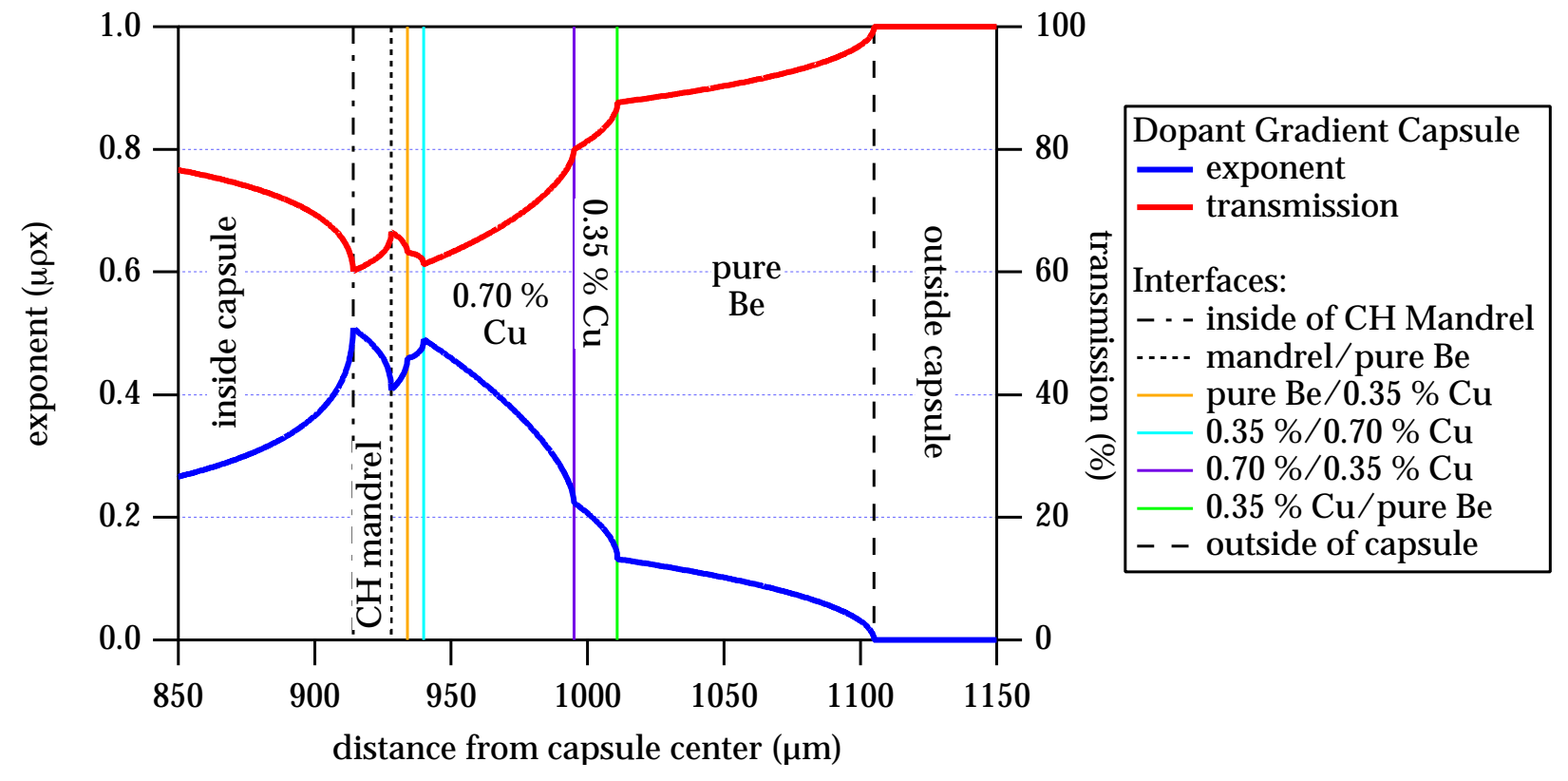

Figure 3. Exponent and transmission plot for $\mathrm{Cu}$-doped $\mathrm{Be}$ graded capsule as shown in Figure 1 and Table 3.

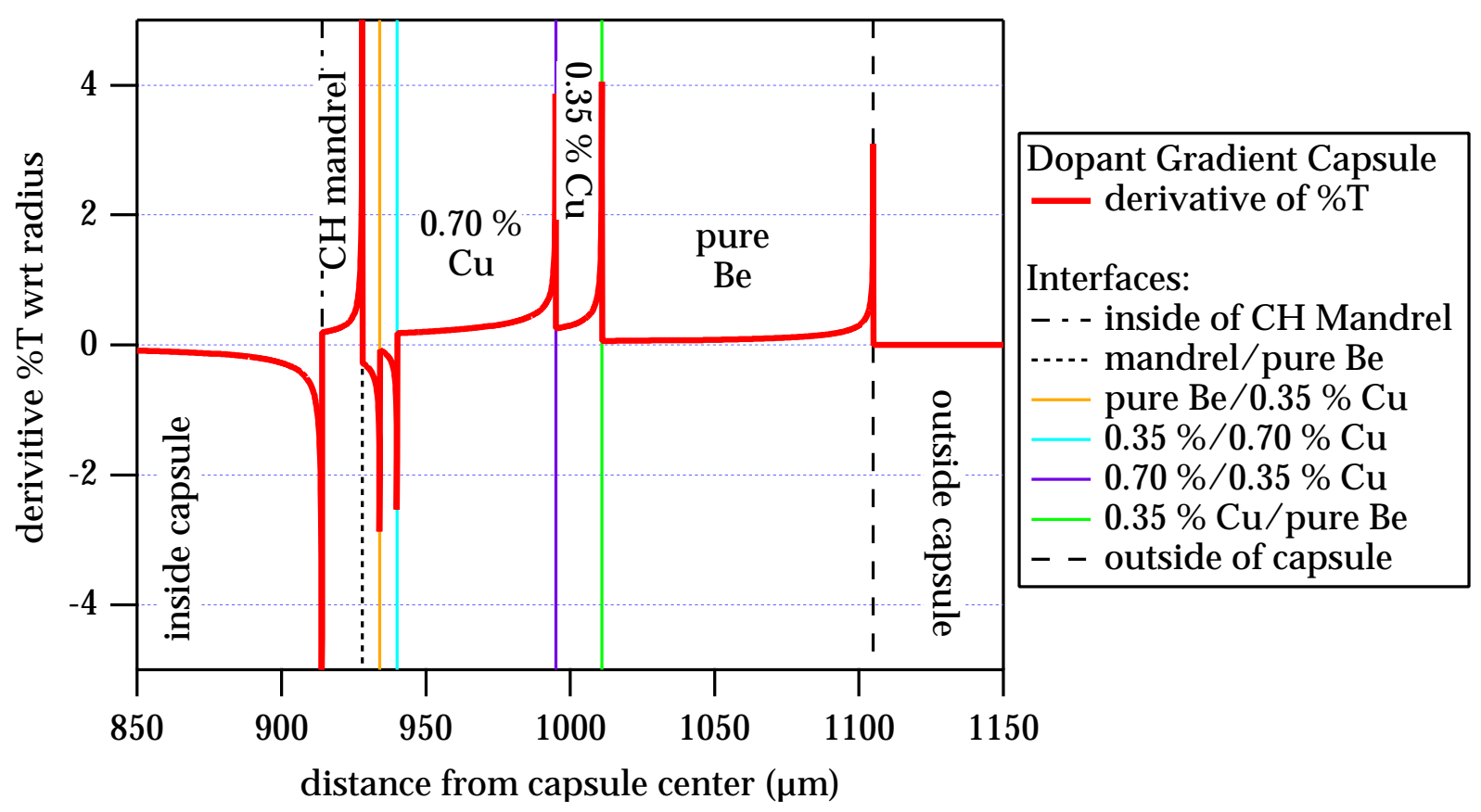

Figure 4. Derivative of transmission data shown in Figure 3. 


\section{Conclusions.}

What is suggested is that standard radiography can see the interfaces and perhaps also measure the concentrations, particularly if standards are produced. These might be shells which have been destructively analyzed in order to associate a given exposure level (x-ray transmission) with concentration. Clearly one can play with the $\mathrm{x}$ ray source to change the photon energy distribution, and this may make the differences more stark. One area of concern is the lateral resolution, which historically has been the order of a $\mu \mathrm{m}$. Work to sharpen this may be fruitful.

Clearly this is not a finished story, but only a beginning. Someone needs to look more carefully at the relevant parameters. Experimentally we will be fabricating $\mathrm{Cu}-$ doped Be gradient capsules in the next several months, as well as Ge-doped CH gradient capsules, with which this analysis can be tested and refined. 


\section{Distribution:}

Tom Bernat L-481

Katie Day L-474

Janelle Gunther L-474

Steve Haan L-023

Bruce Hammel L-481

Jim Hughes L-474

Charlotte King L-474

Steve Letts L-474

Ed Lindsey L-474

Rand McEachern L-481

Mike McElfresh L-371

John Moody L-481

Bob Turner L-479

Russell Wallace L-481

Jason Cooley LANL

Abbas Nikroo GA

Art Nobile LANL

Richard Stephens GA 